\title{
A fé na modernidade conectada
}

\author{
The faith in connected modernity
}

João Eduardo Lamim

\section{Resumo}

A realidade atual é fortemente marcada pela lógica da instantaneidade das coisas e rapidez das relações. Zygmunt Bauman conceitua tais características pela expressão "liquidez", que denota uma sociedade fugaz e volátil. O jornalista Matthew D'Ancona traz à tona um conceito novo, "pósverdade", que manifesta uma construção individual da verdade que, por consequência, legitima uma sociedade fragmentada. As redes sociais são o meio pelos quais tais características se mostram mais fortemente. Apesar de estar inserido em uma realidade por vezes contraditória e desafiadora, o cristão é chamado a encontrar, nas brechas da História, oportunidades para que a ação pastoral da Igreja encontre relevância e lugar de diálogo e ponte para que o Reino de Deus se estenda sobre o mundo e as escolhas de cada ser humano. A partir da opção pastoral de Francisco a Igreja encontra elementos importantes para a concretização da "cultura do encontro" que, a partir do ambiente digital, constrói "pontes" de comunhão e fraternidade.

Palavras-chave: Teologia Pastoral. Modernidade. Pós-verdade. Interatividade. Cultura do Encontro.

\begin{abstract}
The current reality is strongly marked by the logic of the instantaneousness of things and the speed of relationships. Zygmunt Bauman conceives these characteristics by the expression "liquidity", which denotes a fleeting and volatile society. Journalist Matthew D'Ancona brings to a new concept, "post-truth", which manifests an individual construction of the truth that, consequently, legitimizes a fragmented society. Social networks are the means by which these resources show themselves most strongly. Despite being inserted in a sometimes
\end{abstract}


contradictory and challenging reality, the Christian is called to find, in the gaps in history, opportunities for pastoral action by the Church to find information and a place for dialogue and a bridge to the Kingdom of God the world and choices of each human being. From the pastoral option of Francis, the Church finds important elements for the realization of the "culture of encounter" which, from the digital environment, builds "bridges" of communion and fraternity.

Keywords: Pastoral Theology. Modernity. Post-truth. Interactivity. Meeting Culture.

\section{Introdução}

A realidade que vivemos é fruto de grandes transformações. A modernidade se caracteriza pela mudança radical no modo pelo qual o ser humano entende o mundo e a si mesmo: ele passa a entender seu papel de protagonista na história e compreende o progresso como um meio de construção da sua identidade pessoal, comunitária e cultural. Na base de toda construção histórica está o modo como o ser humano entende sua relação com seus semelhantes, com o mundo e com Deus. Como em todo momento histórico, a Igreja sempre se mostrou atenta e preocupada no modo de compreensão e relação da comunidade humana e se coloca, também hoje, como um sinal de Deus, tomando participação ativa nas transformações emergentes.

Percebemos, no modo de caracterizar a realidade atual, a possibilidade de uma leitura a partir das características da cultura digital, da interatividade e das conexões em rede. Neste artigo se procura realizar uma costura entre as abordagens sociológicas e culturais de Zygmunt Bauman, Matthew D'Ancona e Antônio Spadaro, a fim de encontrar um itinerário evangelizador a partir das contribuições do Papa Francisco. A temática das redes sociais toca um dos variados campos da teologia contextual (a fé aplicada aos contextos específicos da vida concreta); porém tende a ser um campo amplamente rico e promissor na pesquisa teológica e científica, pois tem se tornado, paulatinamente, uma realidade constituinte da vida cotidiana e espiritual.

\section{Mudanças e identidade}

Ao visitar os livros de história pode-se encontrar os grandes momentos da humanidade descritos de maneira precisa e delongada, com suas conquistas, 
conflitos e personalidades. E este tempo? Será lembrado por quais características? Que elementos espera-se encontrar em uma análise mais profunda?

O Documento de Aparecida, ao contextualizar a realidade na qual inserese, apresenta o momento de então como um tempo de "mudança de época", expresso em seu nível mais profundo pela mudança cultural, ou seja, pela virada no modo de entender o mundo em suas bases epistemológicas. ${ }^{1}$ Mais que apresentar apenas fatos novos, a mudança de época atinge os critérios com os quais julga-se a realidade,

Fazendo com que não exista tanta clareza do que sejamos, tenhamos, creiamos ou sonhemos. As épocas de mudança atingem o ver a realidade. As mudanças de época atingem o julgar [...] tornando difícil discernir as ações. É porque estamos numa mudança de época que, em diversas instâncias da vida, inclusive na ação evangelizadora, nos sentimos como que apalpando a realidade para chegar a soluções. [...] Isso acontece porque as mudanças de época nos jogam para fora do navio, colocandonos em meio a um mar agitado. Nesta hora, cada um busca a sua tábua de salvação e ... salve-se quem puder. ${ }^{2}$

Tal mudança desdobra-se em muitas dimensões na existência, enquanto modo de pensar e agir, comprometendo a integralidade do ser humano por conta de:

Uma supervalorização da subjetividade individual. [...] O individualismo enfraquece os vínculos comunitários e propõe uma radical transformação do tempo e do espaço, dando papel primordial à imaginação. Os fenômenos sociais, econômicos e tecnológicos estão na base da profunda vivência do tempo, o qual se concebe fixado no próprio presente, trazendo concepções de inconsistência e instabilidade. Deixa-se de lado a preocupação pelo bem comum para dar lugar à realização imediata dos desejos dos indivíduos. ${ }^{3}$

O resultado desta virada de paradigmas encontra eco, especialmente, no enfraquecimento dos laços afetivos e concretos do indivíduo com o mundo e com Deus. Assim, repensa-se um mundo onde nada mais é estável: nem a sociedade e seus valores, nem a verdade, nem a fé, nem si mesmo. ${ }^{4}$ A mudança é desconcertante e torna-se perversa, pois "consiste na passagem do que

\footnotetext{
${ }^{1} \mathrm{DAp} 44$.

${ }^{2}$ AMADO, J. P., A Igreja num mundo em mudança, p. 2-3, grifos do autor.

${ }^{3}$ DAp 44.

${ }^{4}$ AMADO, J. P., A Igreja num mundo em mudança, p. 3-4.
} 
podemos chamar de perene ou eterno para o momentâneo ou passageiro. As diversas situações que vivemos tendem a não serem mais vistas como duradouras, eternas". ${ }^{5} \mathrm{O}$ novo modus vivendi atinge profundamente a maneira de situação da Igreja e seu lugar de fala ao mundo. Atingindo as bases, a mudança em questão toca nas identidades próprias das pessoas e instituições. Nestes "novos tempos" o que significa, portanto, ser cristão, ser religioso, ser leigo ou ser batizado? ${ }^{6}$

A mudança de época torna-se um desafio a superar e a integrar. Superar as mudanças que atentam contra os valores do Evangelho e integrar neste processo "o valor fundamental da pessoa, de sua consciência e experiência, a busca do sentido da vida e da transcendência". ${ }^{7}$ O cristão, ao colocar-se sempre em favor dos valores fundamentais da vida e da pessoa humana, é convidado a confirmar seu testemunho e a voltar-se sempre ao essencial da sua fé e missão.

\subsection{Modernidade líquida}

Zygmunt Bauman, ao utilizar o termo "modernidade líquida", busca caracterizar o seu momento histórico. Podemos estender tal compreensão também à atualidade. A modernidade, para Bauman, é o período que vai sendo preenchido com a busca de respostas e sentido a existência humana, começando com a era da industrialização até hoje. O período atual, portanto, ainda encontra-se sob a égide da modernidade. A modernidade "sólida" é caracterizada pelo início do processo de independência do ser humano e o uso criativo de sua razão, pelo progresso mecânico e pela produção em massa, pelo Estado forte e pelas grandes relações econômicas. A modernidade atual, denominada "líquida", consequência dos progressos da modernidade "sólida", é marcada fortemente pelo individualismo levado ao extremo, pelo progresso acumulativo e opulente, pela quebra da relação espaço-tempo, advinda dos avanços tecnológicos, especialmente das redes digitais, e toda consequência deste. ${ }^{8}$ Diz o próprio Bauman:

Tudo está agora sendo permanentemente desmontado mas sem perspectiva de alguma permanência. Tudo é temporário. É por isso que sugeri a metáfora da liquidez para caracterizar o estado da sociedade moderna: como os líquidos, ela caracteriza-se pela incapacidade de

\footnotetext{
${ }^{5}$ AMADO, J. P., A Igreja num mundo em mudança, p. 3.

${ }^{6}$ AMADO, J. P., A Igreja num mundo em mudança, p. 5.

${ }^{7}$ DAp 52.

${ }^{8}$ PALLARES-BURKE, M. L. G., Entrevista com Zygmunt Bauman.
} 
manter a forma. Nossas instituições, quadros de referência, estilos de vida, crenças e conviç̧ões mudam antes que tenham tempo de se solidificar em costumes, hábitos e verdades auto-evidentes. Sem dúvida a vida moderna foi desde o início desenraizadora. ${ }^{9}$

As características da modernidade em questão estão escancaradas no cotidiano do mundo: correria, insegurança, instabilidade, mudanças repentinas e constantes. Nada mais parece ter estabilidade. Por isso, surge a comparação da realidade com o estado líquido das coisas.

Os líquidos se movem facilmente. Eles fluem, escorrem, esvaem-se, respingam, transbordam, vazam, inundam, borrifam, pingam, são filtrados, destilados; diferentemente dos sólidos não são facilmente contidos - contornam outros obstáculos, dissolvem outros e invadem ou inundam seu caminho. [...] A extraordinária mobilidade dos fluidos é o que os associa à ideia de leveza [...]. Essas são as razões para considerar fluidez ou liquidez como metáforas adequadas quando queremos captar a natureza da presente fase, nova de muitas maneiras, na história da modernidade. ${ }^{10}$

Tal característica própria deste tempo, faz a vida moderna moldar-se aos seus rumos, e requer das pessoas a capacidade sempre desafiante de precisar tratar de todos os assuntos de maneira instantânea e ligeira, mesmo as questões que demandam mais tempo e profundidade. Isto gera uma cisão nas relações e decisões da vida cotidiana, tornando-se nociva porque atinge não só as escolhas e direções a serem tomadas, mas as próprias bases (que até então eram sólidas e seguras) nas quais estruturam-se o modo de compreender o mundo e suas relações, de modo que "o que hoje parece correto e apropriado amanhã pode muito bem tornar-se fútil, fantasioso ou lamentavelmente equivocado". ${ }^{11} \mathrm{~A}$ liquidez traz consigo insegurança e desesperança.

\subsubsection{A liquidez das relações sociais}

Fruto dessa liquidez (talvez o mais instantâneo e doentio) é a instabilidade das relações, as quais moldam a sociedade com elos "frágeis, flexíveis, sem formato, sustentação, concretude. Para Bauman, as relações são

\footnotetext{
${ }^{9}$ PALLARES-BURKE, M. L. G., Entrevista com Zygmunt Bauman.

${ }^{10}$ BAUMAN, Z., Modernidade líquida, p. 8-9.

${ }^{11}$ BAUMAN, Z., Modernidade líquida, p. 6.
} 
formadas como redes, que podem ser tecidas ou desmanchadas facilmente". ${ }^{12}$ Exemplo mais evidente, como que um espelho, desta realidade geral é a sua particularidade encontrada nas redes sociais, marcado por "relações virtuais, onde não se mantém nenhuma proximidade ou contato pessoal. Deste modo, novas possibilidades de sociedade constroem-se, marcadas por interações com validade prevista, descartando-se as relações de longo prazo". ${ }^{13}$ Assim, as relações frágeis e supérfluas são evidenciadas no contexto familiar, amoroso, de amizade, religioso, dentre outros.

Deste modo, Bauman enxerga as redes sociais como um fenômeno decorrente e natural do processo da modernidade e como um instrumento frágil e volátil, justamente porque carece de pessoalidade. ${ }^{14} \mathrm{E}$ o modo de relação estabelecido nesse ambiente digital influencia fundamentalmente "os modos de pensar e de agir, sobre os estilos de vida, sobre a consciência pessoal e comunitária, enfim, sobre a cultura e a própria evangelização". ${ }^{15}$

Porém, na análise de Bauman, a característica da liquidez não é, em seu todo, negativa. A metáfora também pode indicar situações e instrumentos que propiciam uma relação mais pura, transparente, objetiva, franca e sincera. ${ }^{16}$ Deste modo, a metáfora da liquidez nos ensina a olhar os dois lados da realidade: o que não se sustenta, já que pauta-se nos valores individuais, competitivos e incertos ${ }^{17}$ questionando a efemeridade tentadora das redes sociais que não é capaz de esperar para o resultado de seus esforços $;^{18}$ e o que espera tempos melhores, marcado "por um reencantamento do mundo, devolvendo dignidade às emoções e legitimidade ao inexplicável". ${ }^{19}$ De um modo geral pode-se entender que as redes sociais são realidades muito positivas, com a desvantagem de, por parte de seus usuários, conduzir a possíveis fragilidades em suas conexões. ${ }^{20}$ As redes e, consequentemente, seu uso de maneira benéfica ou maléfica dependem dos usuários que delas fizerem uso. É necessário, no entanto, uma formação autêntica, profunda e madura destes usuários para que as redes se tornem oportunidades de conexão e encontro positivos e integradores.

\footnotetext{
12 SILVA JÚNIOR, N., Igreja líquida, p. 62.

${ }^{13}$ SILVA JÚNIOR, N., Igreja líquida, p. 65.

${ }^{14}$ BAUMAN, Z.; MAURO, E., Babel, p. 85.

${ }^{15}$ CNBB, Estudos da CNBB 101, 3.

${ }^{16}$ SILVA JÚNIOR, N., Igreja líquida, p. 73.

${ }^{17}$ OLIVEIRA, D., Entrevista - Zygmunt Bauman.

${ }^{18}$ BAUMAN, Z., Modernidade líquida, p. 21.

${ }^{19}$ BAUMAN, Z., Modernidade líquida, p. 9.

${ }^{20}$ BAUMAN, Z., Modernidade líquida, p. 31.
} 


\subsubsection{A espiritualidade líquida}

Ao falar-se da característica da liquidez no campo da espiritualidade, entra-se na duplicidade de significados já mencionada. Ao passo que pode-se entender a possibilidade de fé limpa, pura, fluída, capaz de enxergar da superfície às dimensões mais profundas, ou, usando a comparação com o termo contábil, representando aquilo que é dado, sem surpresas; também pode "sinalizar uma Igreja sem forma, indefinida, imprecisa, inexplicável no sentido estético, por não estar pronta ou por ainda não ter-se encontrado em sua precisão filosófica, teológica, conceitual". ${ }^{21}$ Assim, torna-se fácil identificar, em meio a uma sociedade líquida, uma espiritualidade que remeta "ao incerto, inseguro, como a água de um lago, que não sustenta, no sentido físico, um corpo que não seja preparado para, por si mesmo, flutuar sobre ela; um local movediço, incapaz de simbolizar um caminho sólido, que dê certezas e direção a quem dele necessite".22

Nesse sentido, faz-se urgente, na incerteza das relações e da conectividade líquida, buscar uma espiritualidade sólida que sirva também de testemunho aos usuários que por ela navegam. Por isso, diante da frenética rapidez, especialmente das informações geradas nas redes sociais, um valor importante a ser recuperado para a espiritualidade é o silêncio. ${ }^{23}$ Francisco, inúmeras vezes em seus pronunciamentos, insiste na necessidade de uma "cultura do encontro", fazendose fundamental a partir da espiritualidade do silêncio como forma de (re)encontro com as dimensões essenciais da existência.

No contexto do mundo moderno, especialmente nas relações midiáticas, Bento XVI também já recordou a importância de equilibrar a participação efetiva na comunicação e o silêncio, falando da "relação entre silêncio e palavra: dois momentos da comunicação que devem-se equilibrar, alternar e integrar entre si para se obter um diálogo autêntico e uma união profunda entre as pessoas". ${ }^{24} \mathrm{O}$ silêncio, especialmente nos ambientes digitais, é o fator basilar para que se crie laços permanentes de amizade, comunhão e evangelização. Ele torna-se "parte integrante da comunicação e, sem ele, não há palavras densas de conteúdo". ${ }^{25} \mathrm{O}$ silêncio tem a capacidade de fazer com que se volte para o caminho interior e se encontre o discernimento entre o superficial e o essencial,

${ }^{21}$ SILVA JÚNIOR, N., Igreja líquida, p. 77.

${ }^{22}$ SILVA JÚNIOR, N., Igreja líquida, p. 77.

${ }^{23}$ GALVÃO, F., O cultivo espiritual em tempos de conectividade, p. 13.

${ }^{24}$ BENTO XVI, PP., Mensagem para o $46^{\circ}$ dia mundial das comunicações sociais.

${ }^{25}$ BENTO XVI, PP., Mensagem para o $46^{\circ}$ dia mundial das comunicações sociais. 
entre a verdade e as fantasias. ${ }^{26}$ E este é sempre um desafio: "a vida conectada, diariamente, testa a nossa capacidade para o recolhimento". ${ }^{27} \mathrm{E}$ o que preocupa, no ambiente das redes sociais, também pode se aplicar ao macrocosmo: "uma sociedade feita apenas de barulho, entretenimento e festa, onde não haja espaço para a solidão de seus habitantes, tende ao desespero, pode virar uma espécie de manicômio da estranheza e da indiferença". ${ }^{28}$

Bauman defende que a incapacidade de conseguir tempo para si em vista de estar sempre em conexão com alguém ou com algo, gera um atrofiamento da criatividade e do prazer pela vida: "Se você está sempre conectado, pode ser que nunca esteja verdadeira e completamente só. Se você nunca está só [...] tem menos chance de ler um livro por prazer, de desenhar um retrato, de contemplar uma paisagem pela janela e imaginar mundos diferentes do seu". ${ }^{29}$

De maneira semelhante explicita Bento XVI, quando exorta para a necessidade de, no uso das redes sociais, encontrar espaços para o silêncio e a reflexão. Ele afirma que as redes sociais são um espaço onde surgem inúmeros questionamentos e, por consequência, milhares de respostas. $\mathrm{O}$ silêncio tem a capacidade, portanto, de "identificar e focalizar as perguntas verdadeiramente importantes", ${ }^{30}$ especialmente aquelas relacionadas ao sentido mais profundo da existência humana: "Quem sou eu? Que posso saber? Que devo fazer? Que posso esperar?". ${ }^{31}$ Mais do que nunca, diante dos grandes desafios da vida moderna que tomam tantos contornos nas redes sociais, cada usuário precisa corresponder ao "convite à reflexão e ao silêncio, que às vezes pode ser mais eloquente do que uma resposta apressada, permitindo a quem se interroga descer até ao mais fundo de si mesmo e abrir-se para aquele caminho de resposta que Deus inscreveu no coração do homem". ${ }^{32}$

A pesquisa teológica sobre as redes digitais tem identificado a própria Internet como um espaço privilegiado para a construção de diálogos e contemplação. Antonio Spadaro, diretor da revista italiana La Civiltà Cattolica, pesquisador na área das comunicações católicas, salienta que "a Rede é um ambiente que, não obstante todos os riscos de alienação, permite experimentar novas formas de contato, de relações e de expressão pessoal". ${ }^{33}$ A característica

${ }^{26}$ GALVÃO, F., O cultivo espiritual em tempos de conectividade, p. 10.

${ }^{27}$ GALVÃO, F., O cultivo espiritual em tempos de conectividade, p. 12.

${ }^{28}$ GALVÃO, F., O cultivo espiritual em tempos de conectividade, p. 12.

${ }^{29}$ BAUMAN, Z., Modernidade líquida, p. 16-17, grifo do autor.

${ }^{30}$ BENTO XVI, PP., Mensagem para o $46^{\circ}$ dia mundial das comunicações sociais.

${ }^{31}$ BENTO XVI, PP., Mensagem para o $46^{\circ}$ dia mundial das comunicações sociais.

${ }^{32}$ BENTO XVI, PP., Mensagem para o $46^{\circ}$ dia mundial das comunicações sociais.

${ }^{33}$ SPADARO, A., Web 2.0, p. 10. 
da interatividade e participação instantânea, democrática e plural se manifesta especificamente nas redes sociais. Estas se tornam, deste modo, o novo rosto da Internet. A rede social é "simples, versátil e adaptável às necessidades e usos diversos", ${ }^{34}$ permitindo "criar, trocar e integrar ideias, notícias e conceitos" 35 de modo ágil e amplo. Este entendimento de 'rede' deve ser compreendido como uma teia 'sem fronteiras', capaz de estender-se de acordo com as relações sempre em construção dialógica. Esta nova cultura emergente é potencialmente comunicativa e criativa. A comunicação hoje adquire característica leve, curta e rápida. Não obstante o olhar positivo que precisa ser lançado sobre esta realidade digital, a criticidade deve ajudar a fundamentar o modo cristão de utilização destas tecnologias. O grande desafio nas redes sociais, especialmente para o cristão, é comunicar o que é perene e duradouro, capaz de responder ao sentido primordial da existência. É preciso comunicar a mensagem com simplicidade e verdade. A comunicação verdadeira deve estar de mãos dadas com a beleza, tomando o devido cuidado para que os conteúdos sejam atrativos e belos sem deixar de serem verdadeiros e manifestar sua importância e relevância. ${ }^{36}$ Spadaro reflete que as redes sociais estão transformando as relações humanas. "A verdadeira mudança não é em nível de tecnologia, mas de seu uso, de sua interpretação". ${ }^{37}$ Além de desafios, o ambiente virtual, especialmente as redes sociais, se colocam como instrumentos para a fé cristã, lidas na perspectiva de frutos do desenvolvimento da capacidade humana, necessitando ser sempre reinterpretadas como ferramentas para o desenvolvimento e humanização dos seus usuários.

Bauman ainda reflete que "nesse nosso mundo sempre desconhecido, imprevisível, que constantemente nos surpreende, a perspectiva de ficar sozinho pode ser tenebrosa; é possível citar muitas razões para conceber a solidão como uma situação extremamente incômoda, ameaçadora e aterrorizante". ${ }^{38}$ Há que se descobrir hoje, portanto, esta via silentis. E tal busca deve ser iniciada no caminho para dentro de si $^{39} \mathrm{O}$ responsáveis pela atual situação e sua consequência são as próprias pessoas. Bauman, para isto, argumenta: "os aparelhos eletrônicos respondem a uma necessidade que não criaram; o máximo que fizeram foi torná-la mais aguda e evidente". ${ }^{40}$ Deste

\footnotetext{
${ }^{34}$ SPADARO, A., Web 2.0, p. 129.

${ }^{35}$ SPADARO, A., Web 2.0, p. 130.

${ }^{36}$ SPADARO, A., Web 2.0, p. 15

${ }^{37}$ SPADARO, A., Web 2.0, p. 12.

${ }^{38}$ BAUMAN, Z., Modernidade líquida, p. 9.

${ }^{39}$ GALVÃO, F., O cultivo espiritual em tempos de conectividade, p. 58.

${ }^{40}$ BAUMAN, Z., Modernidade líquida, p. 9.
} 
modo, ele alerta que a necessidade de conectar-se a todo tempo ou a dependência contínua de música ou informação evidencia "o vazio deixado pela companhia perdida". ${ }^{41}$

Assim, outra busca importante para a espiritualidade necessária para este tempo é a proximidade e a presença, a fim de "dar sentido às tecnologias e usálas adequadamente". ${ }^{42}$ A presença do Evangelho deve ser efetiva e atuante nos ambientes midiáticos, já que sua mensagem é relevante e tem muito a dizer ao usuário conectado e talvez esta seja uma única oportunidade de alguém ter contato com a experiência cristã. ${ }^{43}$

Bauman discorre sobre a falsa presença projetada pelas redes sociais: "nunca mais precisaremos estar sós. O dia inteiro, sete dias por semana, basta apertar um botão para fazer aparecer uma companhia do meio de uma coleção de solitários. Nesse mundo on-line, ninguém jamais fica fora ou distante; todos parecem constantemente ao alcance de um chamado". "Além de falsa presença, Bauman fala da carência de profundidade e sentido de permanência, discorrendo sobre o:

Contato com outras pessoas sem necessariamente iniciar uma conversa perigosa e indesejável. O contato pode ser desfeito ao primeiro sinal de que o diálogo se encaminha na direção indesejada: sem riscos, sem necessidade de achar motivos, de pedir desculpas ou mentir; basta um toque leve, quase diáfano, numa tecla, um toque totalmente indolor e livre de riscos. ${ }^{45}$

Ao passo que dá a impressão de descompromisso, a aparente presença pode também criar a sensação de nunca estar só.

Essa certeza tranquilizadora pode ser mantida e usufruída mesmo quando você está sentado numa sala apinhada de gente, nos corredores de um centro comercial lotado, ou passeando na rua, no meio de um grande grupo de amigos ou de transeuntes; você sempre pode se ausentar espiritualmente e ficar só, ou pode comunicar aos que o rodeiam que deseja ficar fora de contato. ${ }^{46}$

${ }^{41}$ BAUMAN, Z., Modernidade líquida, p. 10.

${ }^{42}$ CNBB, Desafios da Comunicação para a Igreja, introdução, p. 10.

${ }^{43}$ CNBB, Estudos da CNBB 101, 161.

${ }^{44}$ BAUMAN, Z., Modernidade líquida, p. 10.

${ }^{45}$ BAUMAN, Z., Modernidade líquida, p. 10, grifos do autor.

${ }^{46}$ BAUMAN, Z., Modernidade líquida, p. 10, grifos do autor. 
Bauman explicita, assim, o paradoxo da vida conectada. "Você pode escapar da multidão mantendo os dedos ocupados para digitar uma mensagem a ser enviada a alguém que está fisicamente ausente; por isso, nesse momento, não lhe são feitas exigências, nada lhe ocupa a atenção, a não ser o contato, ou passar os olhos numa mensagem que acabaram de lhe enviar". ${ }^{47} \mathrm{O}$ agente de pastoral ${ }^{48}$ para este tempo deve, portanto, ter uma vocação a sadia solidão. "Em meio a tantas conexões, um dia descobriremos, fatalmente, que sempre estivemos on-line para os outros, porém ausentes a nós mesmos". ${ }^{49}$ A conectividade, enquanto equilíbrio entre silêncio (entendido pela via do recolhimento) e presença, começa dentro de si.

O uso consciente e responsável das redes sociais deve ser reflexo de nosso equilíbrio interior, de nossa conexão primeira com nosso eu mais profundo. Quando se vive uma espiritualidade autêntica, as redes se tornam um espaço fecundo de partilha, hospitalidade e relação. Todavia, se nossa fé não possui raízes sólidas, a vida interior facilmente se dilui na liquidez do ambiente digital. ${ }^{50}$

De igual modo, Bauman alerta para a necessidade do equilíbrio entre recolhimento e da presença no ambiente digital: "fugindo da solidão, você deixa escapar a chance da solitude: dessa sublime condição na qual a pessoa pode juntar pensamentos, ponderar, refletir sobre eles, criar - e, assim, dar sentido e substância à comunicação". ${ }^{51}$ E ele continua dizendo: "Mas quem nunca saboreou o gosto da solitude talvez nunca venha a saber o que deixou escapar, jogou fora e perdeu". ${ }^{2}$

Uma espiritualidade digital é purificada através do equilíbrio entre uso e recolhimento, para livrar o usuário do supérfluo e o curar dos excessos. ${ }^{53}$ Para estes tempos de relações líquidas, se faz necessário uma reeducação das escolhas em vista da verdade da existência.

\footnotetext{
${ }^{47}$ BAUMAN, Z., Modernidade líquida, p. 10, grifos do autor.

${ }^{48}$ Quando citados os "agentes pastorais", quer-se dizer das lideranças que ajudam no trabalho da evangelização da Igreja, especialmente no que tange as atividades relacionadas com a Pastoral da Comunicação, principalmente na manutenção, alimentação e suporte das redes sociais.

${ }^{49}$ GALVÃO, F., O cultivo espiritual em tempos de conectividade, p. 13, grifo do autor.

${ }^{50}$ GALVÃO, F., O cultivo espiritual em tempos de conectividade, p. 13.

${ }^{51}$ BAUMAN, Z., Modernidade líquida, p. 11, grifo do autor.

${ }^{52}$ BAUMAN, Z., Modernidade líquida, p. 11.

${ }^{53}$ GALVÃO, F., O cultivo espiritual em tempos de conectividade, p. 13.
} 


\subsection{Pós-verdade}

A fragilidade das relações humanas também evidencia-se no campo epistemológico. É muito complexo atualmente defender uma verdade absoluta, teológica ou perene. A opinião individual tende a sobressair-se sobre a verdade objetiva dos fatos, desconstruindo identidades bem delimitadas e criando uma geração de usuários flexíveis. ${ }^{54}$

Concomitante ao termo "liquidez", para evidenciar aspectos desta modernidade em mudança, recorre-se nesta pesquisa ao conceito de "pósverdade", que em 2016 o Oxford Dictionaries escolheu como sua palavra do ano, por esta ter convergido para si grande atenção, refletindo "o ethos, o humor ou as preocupações daquele ano em particular e ter potencial duradouro como uma palavra de significado cultural". ${ }^{55} \mathrm{O}$ referido dicionário definiu "pósverdade" como forma abreviada para "circunstâncias em que os fatos objetivos são menos influentes em formar a opinião pública do que os apelos a emoção e a crença pessoal". ${ }^{56}$

Seu significado passou, desde quando foi usado pela primeira vez, por uma evolução. Diferentemente de como aborda-se nesta pesquisa, que corresponde ao seu uso atual, na primeira metade do século XX o termo designava o período posterior a um acontecimento importante, especialmente no contexto das revoluções daquele período histórico. O conceito foi utilizado pela primeira vez no sentido atual de "pertencer a um tempo em que o conceito especificado tornou-se sem importância ou irrelevante" 57 em 1992, num artigo na revista The Nations,${ }^{58}$ do dramaturgo sérvio Steve Tesich.

Marcia Tiburi, acerca da época atual, afirma que dentre suas características principais "está a proliferação de fenômenos articulados em torno do prefixo pós". ${ }^{59} \mathrm{O}$ prefixo compreende "eventos e situações que sugerem uma ultrapassagem, até mesmo o abandono de um espaço-tempo, com

\footnotetext{
${ }^{54}$ DUNKER, C., Subjetividade em tempos de pós-verdade, p. 12.

${ }^{55}$ No original: the ethos, mood, or preoccupations of that particular year and to have lasting potential as a word of cultural significance. ENGLISH OXFORD LIVING DICTIONARIES, Word of the Year, grifo do autor, tradução do autor.

${ }^{56}$ No original: circumstances in which objective facts are less influential in shaping public opinion than appeals to emotion and personal belief. ENGLISH OXFORD LIVING DICTIONARIES, Word of the Year 2016 is, tradução do autor.

${ }^{57}$ No original: belonging to a time in which the specified concept has become unimportant or irrelevant. ENGLISH OXFORD LIVING DICTIONARIES, Word of the Year 2016 is, tradução do autor.

${ }^{58}$ OXFORD LIVING DICTIONARIES. Word of the Year 2016 is, tradução do autor.

${ }^{59}$ TIBURI, M., Pós-verdade, pós-ética, p. 97, grifo do autor.
} 
a criação de um outro, de uma nova experiência, que em tudo parece ter desmontado o que nos era dado como conhecido". ${ }^{60}$

Christian Dunker retoma as acepções antigas de "verdade" para esclarecer o termo em suas significações atuais.

Para os antigos, a verdade tinha três conotações. Ela era tanto revelação grega (alethéia) de uma lembrança esquecida quanto a precisão latina do testemunho (veritas) e ainda a confiança judaico-cristã da promessa (emunah). Por isso a verdade tem três opostos diferentes: a ilusão, a falsidade e a mentira. A pós-verdade é algo distinto do mero relativismo, e sua dispersão de pontos de vista, todos igualmente válidos, ou do pragmatismo, com sua regra maior de que a eficácia e a eficiência impõem-se às nossas melhores representações do mundo. Ela também não é apenas a consagração do cinismo no poder, com sua moral provisória, capaz de gerenciar o pessimismo, no atacado da tragédia humana, em proveito de vantagens obtidas no varejo narcísico. A pósverdade depende, mas não se resume a isso, porque ela acrescenta uma ruptura entre os três regimes de verdade e seus contrários. ${ }^{61}$

A pós-verdade, desse modo, não é apenas a inversão das compreensões tradicionais da verdade ou uma nova dimensão desta. ${ }^{62}$ Ela torna-se a corrupção das relações da/com a verdade.

\subsubsection{Pós-verdade: a degeneração da modernidade líquida}

O conceito de "pós-verdade" ajuda a entender o fenômeno cultural atual: tempo de manipulação das informações de modo premeditado, apelativo e distorcido da verdade objetiva para benefício exclusivo ou para causar determinado impacto. O uso original e mais recorrido é quanto a realidade política e econômica, exemplificado na manipulação das informações e opinião nas mídias sociais durante as eleições de Donad Trump e na utilização das campanhas emotivas voltadas à população, para convencer dos benefício do Brexit, a saída do Reino Unido da União Europeia. ${ }^{63}$ D'Ancona afirma que esta é "a política da pós-verdade em seu estado mais puro: o triunfo do visceral sobre o racional, do enganosamente simples sobre o honestamente complexo". ${ }^{64} \mathrm{Tal}$

\footnotetext{
${ }^{60}$ TIBURI, M., Pós-verdade, pós-ética, p. 97.

${ }^{61}$ DUNKER, C., Subjetividade em tempos de pós-verdade, p. 18-19, grifos do autor.

${ }^{62}$ DUNKER, C., Subjetividade em tempos de pós-verdade, p. 20.

${ }^{63}$ CASTRO, J. C. L., Pós-verdade e o papel do jornalismo.

${ }^{64}$ D’ANCONA, M., Pós-Verdade, p. 29.
} 
engenhosidade torna-se tão organizada que conta com um aparato em torno a si, inclusive um mercado específico.

O panorama apresentado pelo autor se torna muito evidente no ambiente das redes sociais, a partir da "difusão sistemática de mentiras por organizações de fachada que atuam a favor de grupos de interesse que desejam suprimir a informação precisa e impedir que outros grupos ajam contra eles". ${ }^{65}$ D'Ancona afirma, citando o jornalista investigativo Ari Rabin-Havt, que o esquema do mercado organizado em torno deste fenômeno é um verdadeiro "ataque coordenado e estratégico, planejado para esconder a verdade, confundir o público e criar controvérsia onde nenhuma antes existia" ${ }^{66}$ Pós-verdade não torna-se a inversão da verdade pela mentira, mas a manipulação de ambas.

Neste mesmo rumo, a expansão do mercado da pós-verdade coincidiu com a explosão do ambiente digital, especialmente com as redes sociais, encontrando ali "o meio mais barato e mais rápido de publicação" ${ }^{67}$ e divulgação de seus conteúdos. "A web é o vetor definitivo da pós-verdade, exatamente porque é indiferente à mentira, à honestidade e à diferença entre os dois" ${ }^{68}$ A pós-verdade vai, sorrateiramente, tomando forma e lugar, revelando suas características marcantes. "A questão não é determinar a verdade por meio de um processo de avaliação racional e conclusiva. Você escolhe sua própria realidade, como escolhe-se a comida de um bufê. Também seleciona sua própria mentira, de modo não menos arbitrário". ${ }^{69}$

$\mathrm{O}$ fenômeno da pós-verdade pode confundir-se com as fake news. Enquanto aquela consiste num mascaramento da verdade por interesse ou audiência, uma redução manipulada da verdade, as fake news são mentiras escalonadas em tamanha perspectiva que passam a ser creditadas e assumidas como verdadeiras. ${ }^{70}$ Porém, não se pode negar que as fake news são consequências do fenômeno moderno caracterizado pela instabilidade, aparência e sensacionalismo midiático.

No espaço das redes sociais, a pós-verdade se fortalece e ganha seu público-mercado. Falar de pós-verdade:

Trata-se de falar de uma verdade útil. Da verdade consumível e consumida. A verdade possível quando a forma mercadoria dita que ela mesma é a

${ }^{65}$ D'ANCONA, M., Pós-Verdade, p. 46.

${ }^{66}$ D'ANCONA, M., Pós-Verdade, p. 46.

${ }^{67}$ D'ANCONA, M., Pós-Verdade, p. 50.

${ }^{68}$ D'ANCONA, M., Pós-Verdade, p. 55, grifo do autor.

${ }^{69}$ D’ANCONA, M., Pós-Verdade, p. 57.

${ }^{70}$ FRANCISCO, PP., Mensagem para o $52^{\circ}$ Dia Mundial das Comunicações Sociais. 
verdade. A possibilidade de uma verdade caixa alta, capaz de nos explicar o desconhecido, não vem mais ao caso. Contentamo-nos com pouco. E esse pouco é a pós-verdade. A verdade que podemos aceitar. ${ }^{71}$

Bauman já advertia, falando da modernidade líquida e da volatividade que tinham as informações no ambiente virtual, sobre a enxurrada destas sobre os usuários e sua capacidade de o submergir. Deste modo, a pós-verdade surge como que por consequência necessária da modernidade líquida. "A aliança bífida do pós-modernismo pedia por um substrato moral que pudesse reunir as escolhas políticas e econômicas com os progressos científicos e cognitivos". ${ }^{72}$ A pós-verdade torna-se o instrumento para legitimação das diferenças criadas pela modernidade e suas nuances e desenvolvimentos.

Pós-verdade, redes sociais e uma sociedade de consumo desenfreado são realidades que desafiam os cristãos a repensar o mundo que os cerca e a ser agentes da nova evangelização. ${ }^{73}$ Para tal, faz-se urgente a redescoberta da missão cristã e sua importância nos ambientes digitais. A pós-verdade precisa ser encarada como uma nuance do grande fenômeno que é a modernidade atual, líquida, e enfrentada em prol dos que, conscientes de si e de seu insondável mistério, buscam bases sólidas para sua existência.

\section{A superação a partir da fé cristã}

Também no fenômeno da pós-verdade, sendo processo natural da modernidade e construção da "sociedade do espetáculo", há que reconhecer também alguns aspectos positivos desta possível relativização da hegemonia da Verdade. Este modo de pensar pós-moderno estimulou

A ideia de que uma sociedade cada vez mais pluralista precisaria reconhecer e prestar atenção às múltiplas vozes: as histórias de gênero, minorias étnicas, orientação sexual e tradição cultural. Os pensadores pós-modernos como Richard Ashley, Derrida e Foucault exortaram seus leitores a questionar e desconstruir a linguagem, o idioma visual, as instituições e o saber adquirido, e perguntar como as palavras, as histórias, a arte e a arquitetura podem preservar formas de poder e hegemonia, às quais permaneceríamos cegos normalmente. ${ }^{74}$

\footnotetext{
${ }^{71}$ TIBURI, M., Pós-verdade, pós-ética, p. 107.

${ }^{72}$ DUNKER, C., Subjetividade em tempos de pós-verdade, p. 16.

${ }^{73}$ DAp 123.

${ }^{74}$ D’ANCONA, M., Pós-Verdade, p. 85, grifo do autor.
} 
Ainda que a capacidade de pensar de modo plural e aberto tenha sido uma conquista, não se deve esconder o fato de que tal movimento, como se disse até aqui, desgastou a noção de verdade e desestruturou o pensamento seguro e a realidade objetiva, afirmando que tudo é fruto da construção coletiva. " ${ }^{75}$ se tudo é um constructo social, então, quem vai dizer o que é falso? O que impedirá o fornecedor da notícia falsa de afirmar ser um obstinado digital combatendo a hegemonia perversa da grande mídia?"76

De fato, com a análise em questão não se pode querer, ainda hoje, que tudo seja enquadrado unicamente pela realidade objetiva ou por uma análise anacrônica, mas deve-se propiciar um espaço mais democrático e, oportunamente aberto ao diálogo. Aqui pode-se observar o paradoxo em questão: "a pós-verdade explora uma característica muito curiosa da internet que é sua relativa flutuação de autoridade, o que, considerado por outro ângulo, é um de seus aspectos mais democráticos" ${ }^{77}$ A abertura à construção de um diálogo divide espaço com a volatividade dos seus próprios argumentos.

Em uma sociedade multiétnica e multireligiosa, o objetivo nunca pode ser impor uniformidade absoluta: isso seria indefensável eticamente, assim como terrivelmente enfadonho. O objetivo é identificar o cerne das normas culturais, dos deveres legais e das responsabilidades sociais ao qual todos os cidadãos devem aderir, independentemente de suas opiniões particulares. A diversidade é, e vai continuar a ser, um dado básico, mesmo com a nova coorte de nativistas afirmando o contrário. $\mathrm{O}$ desafio é identificar o denominador comum da troca social, intelectual e prática sobre a qual todos concordam. A pós-verdade alimenta a alienação, o desarranjo e o silêncio entorpecedor. A maior missão cívica que temos pela frente é esvaziar a calha. ${ }^{78}$

Levando em conta os argumentos prós e contras, a atitude cristã pode ser sempre tentada ao passivismo entorpecente. De igual modo, não se pode aderir a uma acédia ${ }^{79}$ e conformação com as mudanças avassaladoras.

Nossa própria era da pós-verdade é uma amostra do que acontece quando uma sociedade afrouxa em sua defesa dos valores que sustentam sua coesão, ordem e progresso: os valores da verdade, honestidade e

\footnotetext{
75 D’ANCONA, M., Pós-Verdade, p. 85.

${ }^{76}$ D'ANCONA, M., Pós-Verdade, p. 85, grifo do autor.

${ }^{77}$ DUNKER, C., Subjetividade em tempos de pós-verdade, p. 40.

${ }^{78}$ D'ANCONA, M., Pós-Verdade, p. 97-98.

${ }^{79}$ EG 81-82.
} 
responsabilização. Esses valores não são autossustentáveis. Sua manutenção é produto da decisão, ação e colaboração do ser humano. ${ }^{80}$

A era da pós-verdade é um desafio e "acima de tudo, um fenômeno emocional. Diz respeito à nossa atitude em relação à verdade, e não à própria verdade" ${ }^{81}$ Por isso, deve tocar a todos enquanto usuários digitais e cristãos. "A história da humanidade é a história da batalha entre indiferença e o compromisso, no interior das pessoas e também entre elas". ${ }^{82}$ Por isso, a batalha a travar-se no mundo atual é cultural e espiritual, de modo que a experiência cristã contribua para a compreensão da vida e da missão dos cristãos de modo integral e profundamente conectado em suas mais variadas dimensões e contextos hodiernos, rejeitando qualquer modelo fragmentado de vivência cristã e de "aparência religiosa", derivada do pensamento líquido e da pósverdade. Exemplo disso encontra-se na dimensão bíblico-pastoral. É cada vez mais comum alguns cristãos partirem de exegeses pessoais para posteriormente se buscar amparo bíblico com versículos que justificam suas opiniões, "criando uma versão favorável a si próprio", ${ }^{83}$ tornando-se tão dogmatizadas que acabam por fundar novas escolas interpretativas, destruindo a unidade da fé. Na maioria desses casos, "trata-se duma falsa narração", ${ }^{84} \mathrm{em}$ vista de "procurar os meios para reforçar a sua posição e silenciar as vozes dissonantes. É o grito que nasce de maquilhar a realidade, pintando-a de tal maneira que acabe por desfigurar o rosto de Jesus". ${ }^{85}$ Geralmente em torno de um exegeta midiático, há seguidores que reproduzem suas elucubrações teológicas, pastorais, subjetivas e até corporais. A primazia é da opinião e não da Palavra; a precedência é da aparência e não da essência.

Outro modo exemplificativo (aqui secular) da precedência da opinião sobre a verdade objetiva é o mecanismo de busca e compartilhamento mais comum nas redes sociais: a hastag.

A mídia social e os mecanismos de busca, com seus algoritmos e hashtags, tendem a nos dirigir para o conteúdo de que vamos gostar e para as pessoas que concordam conosco. [...] A consequência é que as

\footnotetext{
${ }^{80}$ D’ANCONA, M., Pós-Verdade, p. 100.

${ }^{81}$ D'ANCONA, M., Pós-Verdade, p. 110-111.

${ }^{82}$ D'ANCONA, M., Pós-Verdade, p. 124-125, grifo do autor.

${ }^{83}$ FRANCISCO, PP., Homilia para a celebração do Domingo de Ramos e da Paixão do Senhor.

${ }^{84}$ FRANCISCO, PP., Homilia para a celebração do Domingo de Ramos e da Paixão do Senhor.

${ }^{85}$ FRANCISCO, PP., Homilia para a celebração do Domingo de Ramos e da Paixão do Senhor, grifo do autor.
} 
opiniões tendem a ser reforçadas, e as mentiras, incontestadas. Definhamos no assim chamado filtro bolha. De fato, nunca houve um modo mais rápido e mais poderoso de espalhar uma mentira do que postála on-line. ${ }^{86}$

De fato, as características apresentadas pelos autores ao longo desse artigo, revelam uma realidade cultural desafiadora. É:

Uma cultura complexa e paradoxal que, por um lado, exalta o relativismo, flerta com o hedonismo e tangencia o niilismo e, por outro lado, assume posturas fundamentalistas e conservadoras. Uma cultura instável, marcada pela vulnerabilidade da família, pelo enfraquecimento de instituições tradicionais, pela banalização perversa da violência, por relacionamentos afetivos superficiais, desprovidos de envolvimento profundos e compromissados. Uma cultura que pode lançar o humano, o jovem a uma profunda crise de sentido existencial. ${ }^{87}$

Francisco reitera a necessidade de reencontrar nas conexões da rede a identidade comunitária do mundo e da Igreja. Ele afirma que "não basta multiplicar as conexões para ver crescer também a compreensão recíproca", 88 mas é preciso "reencontrar a verdadeira identidade comunitária na consciência da responsabilidade que temos uns para com os outros". ${ }^{89}$ Reitera ainda que:

O uso da social web é complementar do encontro em carne e osso, vivido através do corpo, do coração, dos olhos, da contemplação, da respiração do outro. Se a rede for usada como prolongamento ou expetação de tal encontro, então não se atraiçoa a si mesma e permanece um recurso para a comunhão... abrir o caminho ao diálogo, ao encontro, ao sorriso, ao carinho... Esta é a rede que queremos: uma rede feita, não para capturar, mas para libertar, para preservar uma comunhão de pessoas livres. ${ }^{90}$

Diante desse conjunto de fatores, mais que necessário se faz uma ação eclesial comprometida com a Verdade do Evangelho, especialmente no contexto das redes sociais, entendidas como uma "nova natureza humana", ${ }^{91}$ a

\footnotetext{
${ }^{86}$ D’ANOCONA, M., Pós-Verdade, p. 53, grifo do autor.

${ }^{87}$ OLIVEIRA, A. F., Juventude e novos contextos culturais, p. 284-285.

${ }^{88}$ FRANCISCO, PP., Mensagem para o $53^{\circ}$ Dia Mundial das Comunicações Sociais.

${ }^{89}$ FRANCISCO, PP., Mensagem para o $53^{\circ}$ Dia Mundial das Comunicações Sociais.

${ }^{90}$ FRANCISCO, PP., Mensagem para o $53^{\circ}$ Dia Mundial das Comunicações Sociais.

91 TIBURI, M., Pós-verdade, pós-ética, p. 120.
} 
"ágora digital". ${ }^{92}$ Mais forte que a mentira e a distorção de informações é a Verdade anunciada com clareza, convicção, criatividade e ousadia. Pode-se perguntar: "é possível viver a fé num contexto de mobilidade, de transitoriedade?"93 A "cultura do encontro" de Francisco é um apelo para a retomada de uma comunhão mais profunda e estrutural, seja na Igreja ou fora dela. A realidade conectada realiza-se plenamente a partir do encontro sincero e dialogal com os sujeitos e as dimensões da existência humana. As tecnologias não podem dominar os seres humanos, mas devem servi-los e ajudá-los no processo pessoal e comunitário de integração universal.

\section{Conclusão}

Neste contexto de mudança de época, marcada pela instantaneidade e rapidez de informação, a internet também é atingida pela transformação frenética do mundo. "A internet está sempre se desenvolvendo cada vez mais resolutamente e se transformando numa rede de contatos sociais, uma plataforma relacional". ${ }^{94}$ Contra o movimento de relativização e esvaziamento da verdade e dos valores fundamentais para a fé cristão, se faz urgente retornar "a um estado personalista da verdade, resgatar suas raízes na família, retomando o tempo em que a verdade era definida pela identidade do autor que a enuncia". 95

Numa realidade marcada pela mudança constante e relações interativas abertas em significados, as redes sociais se apresentam hoje como parte constitutiva da vida moderna. A concepção de mundo, de pessoa e de fé cristã passa, inexoravelmente, pelos conceitos de interatividade, conectividade, rede e comunhão. A modernidade, com seus desafios e limitações, se coloca como uma oportunidade, para as pessoas, de construir laços de relações mais abrangentes, integrativas e abertas. Desse modo, a fé cristã, como semente fecunda em todos os momentos da história do mundo, especialmente os mais críticos, deve encontrar seu lugar e relevância na vida hodierna, para ajudar os homens e mulheres do nosso tempo a responderem, com coerência e profundidade, as suas questões existenciais, indicar caminhos seguros diante de seus anseios e dúvidas e os acompanhar a uma rica experiência com Deus nas sendas da fé.

\footnotetext{
92 TIBURI, M., Pós-verdade, pós-ética, p. 119.

${ }^{93}$ AMADO, J. P., A Igreja num mundo em mudança, p. 6.

${ }^{94}$ SPADARO, A., Web 2.0, p. 9, grifo do autor.

${ }^{95}$ DUNKER, C., Subjetividade em tempos de pós-verdade, p. 41.
} 
Diante das relações frias e transitórias, como caracteriza Bauman, as deste tempo atual, e das construções subjetivas de verdade, justiça e fraternidade, como indica D'Ancona, a Igreja, de modo especial através da formação madura e profunda de seus agentes, busca elementos comuns na vida secular para ajudar a construir bases sólidas para uma convivência fraterna, integradora e de comunhão. $\mathrm{O}$ usuário conectado anseia por respostas; busca insaciavelmente por permanência e eternidade. A fé encontra neste anseio a oportunidade que precisa para anunciar, sobre os telhados, via cabos, via satélite, $W i-f i$ ou até $5 \mathrm{G}$, sua mensagem de Verdade e esperança. A lógica da rede é a oportunidade mais propícia atualmente para que a verdade do Evangelho encontre os corações dos usuários.

\section{Referências bibliográficas}

AMADO, J. P. A Igreja num mundo em mudança. Goiânia: CNBB, 2011. Disponível em: $\quad<\mathrm{http}: / /$ cnbbjoomla.sitesparresia.com/wpcontent/uploads/sites/85/2011/10/A_Igreja_num__mundo_em_mundana__Pe.Joel_Portella.pdf>. Acesso em: 17 set. 2019.

BAUMAN, Z. Modernidade líquida. Rio de Janeiro: Jorge Zahar, 2001.

BAUMAN, Z.; MAURO, E. Babel: entre a incerteza e a esperança. Rio de Janeiro: Zahar, 2016.

BENTO XVI, PP. Mensagem para o $46^{\circ}$ dia mundial das comunicações sociais. Vaticano, 20 mai. 2012. Disponível em: <http://w2.vatican.va/content/benedict$\mathrm{xvi} / \mathrm{pt} / \mathrm{messages} /$ communications/documents/hf_ben-xvi_mes_20120124_46thworld-communications-day.html >. Acesso em: 14 out. 2019.

CASTRO, J. C. L. Pós-verdade e o papel do jornalismo: neoliberalismo, Brexit/Trump e redes sociais. São Paulo: ECA/USP, 2017. Disponível em: $<$ http://sbpjor.org.br/congresso/index.php/sbpjor/sbpjor2017/paper/viewFile/6 87/508>. Acesso em: 11 ago. 2019.

CELAM. V Conferência Geral do Episcopado Latino-americano e do Caribe. Documento de Aparecida: texto conclusivo. Brasília: CNBB, 2008.

CNBB. A comunicação na vida e missão da Igreja no Brasil. São Paulo: Paulus, 2011. (Estudos da CNBB 101).

D'ANCONA, M. Pós-Verdade: a nova guerra contra os fatos em tempos de fake news. Barueri: Faro Editorial, 2018. 
DUNKER, C. Subjetividade em tempos de pós-verdade. In: DUNKER, C. et al. Ética e pós-verdade. Porto Alegre: Dublinense, 2017. p. 9-41.

ENGLISH. Word of the Year 2016 is. Disponível em: $<$ https://en. oxforddictionaries.com/word-of-the-year/word-of-the-year-2016>. Acesso em: 13 ago. 2019.

ENGLISH OXFORD LIVING DICTIONARIES. Word of the Year. Disponível em: $<$ https://en. oxforddictionaries.com/word-of-the-year $>$. Acesso em: 13 ago. 2019.

FRANCISCO, PP. Exortação Apostólica Evangelii Gaudium. São Paulo: Paulinas, 2013.

FRANCISCO, PP. Homilia para a celebração do Domingo de Ramos e da Paixão do Senhor. Vaticano, 25 mar. 2018. Disponível em: $<$ https://w2.vatican.va/content/francesco/pt/homilies/2018/documents/papafrancesco_20180325_omelia-palme.html>. Acesso em: 12 nov. 2020.

FRANCISCO, PP. Mensagem para o $5^{\circ}$ Dia Mundial das Comunicações Sociais. Vaticano, 13 mai. 2018. não paginado. Disponível em: $<$ http://w2.vatican.va/content/francesco/pt/messages/communications/docume nts/papa-francesco_20180124_messaggio-comunicazioni-sociali.html >. Acesso em: 12 nov. 2019.

FRANCISCO, PP. Mensagem para o LIII Dia Mundial das Comunicações Sociais. Vaticano, 2 jun. 2019. não paginado. Disponível em: $<$ http://w2.vatican.va/content/francesco/pt/messages/communications/docume nts/papa-francesco_20190124_messaggio-comunicazioni-sociali.html>. Acesso em: 12 nov. 2020.

GALVÃO, F. O cultivo espiritual em tempos de conectividade. São Paulo: Paulus, 2018.

OLIVEIRA, A. F. Juventude e novos contextos culturais. In: PESSINI, L.; ZACHARIAS, R. (Org.). Ética teológica e juventudes: interpelações recíprocas. Aparecida: Santuário, 2013. p. 271-290.

OLIVEIRA, D. Entrevista - Zygmunt Bauman. Disponível em: $<$ https://revistacult.uol.com.br/home/entrevis-zygmunt-bauman/>. Acesso em: 27 nov. 2019.

PALLARES-BURKE, M. L. G. Entrevista com Zygmunt Bauman. Revista Tempo Social, v. 16, n. 1, p. 301-325, jun. 2004. Disponível em: 
$<$ http://www.scielo.br/scielo.php?script=sci_arttext\&pid=S010320702004000100015\&lng=pt\&nrm=iso\&tlng=pt>. Acesso em: 21 nov. 2019.

SILVA JÚNIOR, N. Igreja líquida: uma leitura da Igreja moderna através do Neopentecostalismo. Ciberteologia, v. 7, n. 34, p. 61-77, abr./jun. 2011. Disponível em: <https:/pt.scribd.com/document/316457049/Igreja-liquidauma-leitura-da-Igreja-moderna-atraves-do-Neopentecostalismo $>$. Acesso em: 21 set. 2019.

SPADARO, A. Web 2.0: redes sociais. São Paulo: Paulinas, 2013.

TIBURI, M. Pós-verdade, pós-ética: uma reflexão sobre delírios, atos digitais e inveja. In: DUNKER, C. et al. Ética e pós-verdade. Porto Alegre: Dublinense, 2017. p. 95-123.

João Eduardo Lamim Mestrando em Educação e Tecnologias Digitais pela Universidade da Região de Joinville Bolsista PROSUC/CAPES Joinville / SC - Brasil E-mail: joaoedurs1@gmail.com

Recebido em: 12/06/2020

Aprovado em: 16/12/2020 